such a way as to make the organization a more effective focus for space research in Europe. One of the strengths of CERN is that countries which have paid their subscriptions are tempted to get the best value for their investment by carrying out as much work as possible at the central establishment (which has not, of course, brought strictly national activity in high energy physics to a halt). If there were an incentive like this for ESRO, that organization would be enormously strengthened.

It is also important that there should now be a cool appraisal of the commercial benefits of building large launching rockets in Europe. As things are, the ELDO launcher casts a long shadow over everything. People are naturally reluctant to acknowledge that the usefulness of this machine is limited after so much money has been spent on it. The result is that plans for satellite development in ESRO, and plans for launching communications satellites in Europe, are being made to hang on this one rocket. Even at this late stage, however, it is entirely possible that it would be better to start again from scratch on the development of another rocket. That is something which ought to be considered. It is also possible that a suitable organization in Europe could make a sensible (and lasting) agreement with the United States on the use of even bigger rockets. Certainly this is a possibility which ought to be explored. Much will depend on the form of the revised INTELSTAT agreement, which is certain by the seventies to seem on both sides of the Atlantic to be too much dominated by the United States. But in this sense, some hard work now on the diplomacy of international communications could help enormously to simplify the problem of deciding what kinds of rockets, if any, should be developed and built independently in Europe. To begin with, however, it is essential that these discussions should be undertaken on a European basis. The common interest of the non-rocket countries is too powerful for any other course to be acceptable.

\section{HOW BIG IS CHINA?}

How soon will China be a nuclear power to be reckoned with ? The prophecies which the Joint Committee on Atomic Energy has been making about the development of nuclear weapons and missiles in mainland China (see page 805) are sobering but not much of a surprise. For a decade now, Chinese statesmen have made no secret of their intention to develop a strategic striking force. Indeed, on several occasions since the official opening in 1958 by Mr Kruschev of the Russian research reactor in Peking, commentators elsewhere have been inveigled into the assumption that Chinese ambitions had already been translated into fact. Although it is now clear that preparations for the manufacture of nuclear explosives were well under way even before 1958, the course of events since then has not in any way been unexpected. The interval of time between the first fission explosion and the first fusion explosion in China may have been shorter than elsewhere, but that is a simple consequence of what must have been an explicit decision in China that the only weapons worth having are thermonuclear weapons. Certainly the obvious difference between the speed of development in China and in France seems to stem directly from Chinese confrontation on the building of diffusion plants for the manufacture of fissile uranium. The joint committee is understandably puzzled that the French are making what seems to be heavy weather of the production of a thermonuclear weapon, but it is probably prudent-even fair-to remember that the origin of the French decision to manufacture nuclear weapons was clouded, to say the best of it. To begin with, the French government talked chiefly of tactical uses for nuclear weapons. Given Chinese single-mindedness, it is not surprising that China has forged ahead with the manufacture of nuclear explosives of all kinds.

The development and manufacture of missiles are another matter. The joint committee seems to have convinced itself that the Chinese are already possessed of medium range ballistic missiles and that rockets able to travel greater distances will be in service in the early seventies. No doubt the committee has access to unpublished information about developments in China, and there is no question that the news it has to give of the development of delivery systems for nuclear weapons is potentially important. Because the Chinese aircraft industry is as yet comparatively unsophisticated, it has always been evident that China could not become an effective nuclear power without some machinery for the delivery of nuclear explosives. It would be entirely consistent with the policy of seeking to become a nuclear power as soon as possible if the Chinese had decided not to bother with the development of aircraft but to go straight for long range missiles. Nevertheless, it would be surprising if China were able by the early seventies not merely to design and prove a long range missile, but to manufacture it in large numbers and then integrate it into a strategic striking force. Experience elsewhere shows that there is often a lag of several years between the first appearance of a new sophisticated weapon and its effective deployment in the field. This is why it is probably safe to think that it will be nearer the middle of the next decade than the beginning when the Chinese are able to level a credible threat against other strategic nuclear powers, to the west or to the east of China. This no doubt is why Mr Robert McNamara in the United States has been able to insist that an antiballistic missile system will not be strictly necessary before the mid-seventies.

A lot can happen before then. One possibility is. of course, that domestic troubles in China may prevent the Chinese government from maintaining a coherent and consistent defence policy but it would be rash for people outside China to rely on that. It is, however, more than likely that long before the Chinese government would wish directly to pose a missile threat 
against-say-the United States, it will find itself preoccupied with more immediate and more local problems. In particular, the Chinese government is likely to find itself increasingly made militarily impotent in the immediate neighbourhood of mainland China by the lack of advanced conventional weapons. For one thing, this deficiency is likely to limit the extent to which the Chinese are able to think of using their new nuclear explosives even in the affairs of south-east Asia.

In other words, one of the immediate and somewhat paradoxical consequences of the speed with which nuclear explosives have been developed in China may well turn out to be a recognition that single-mindedness has created a lopsided military apparatus. Obviously it would be folly to hope that the Chinese will noticeably slacken their efforts on nuclear weapons for the sake of a more balanced programme, but the next few years are likely to bring some sharp reminders that the mere possession of nuclear weapons does not make up for a lack of conventional strength. China, like the other nations which have developed nuclear weapons for themselves, will soon begin to learn that nuclear explosives do not bring instant prowess.

What will happen after that? If it is reasonable to assume that Chinese nuclear weapons will be substantial by the middle seventies, it is natural to expect that the existing nuclear powers will be forced in some way to respond. The development and deployment of antjballistic missiles in the United States is one obvious possibility, although it is not immediately obvious why the kind of strategic balance which has developed between the Soviet Union and the United States should not also help to nullify the Chinese threat. Is it so entirely outrageous to look for some kind of dialogue between China and the other members of the nuclear club ? In practice it is hard to think that the isolation of China from the rest of the world can persist unchanged for yet another decade. In the long run, and possibly in the immediate future as well, it may be more profitable for the rest of the world to respond to what is happening in China by talk rather than by the development of nullifying hardware.

\section{MOLECULAR MODELS}

A realization of the importance of molecular model building was a major factor in Pauling's determination of the $\alpha$-helix of proteins and Watson and Crick's discovery of the structure of DNA. But model building-apart from providing a way of refining molecular structures which are being determined by X-ray crystallography and giving tangible representations of the final molecular structure - can by itself, in the right hands, provide a method for predicting the probable atomic structures of macromolecules which, for one reason or another, cannot be directly determined by X-ray diffraction. Such predictive model building is, bowever, fraught with pitfalls and only when it is treated as a strict discipline can any reliance be placed on the results it yields. Of necessity, assumptions must replace data, and the validity of a model structure entirely depends on the validity of the principal assumptions; but a model must in addition bring together every scrap of relevant chemical and stereochemical data that is available, no matter how obtained, and synthesize it into a coherent whole.

The elucidation of a unique structure of a small but very interesting part of the transfer-RNA molecule, the anticodon loop, by Fuller and Hodgkin, which is reported on page 817 , is a case in point. Crystallographic analyses of $t$ RNA are impossible simply because, despite numerous efforts and some red herrings, it has so far proved impossible to erystallize the material. However, since Holley and his collaborators determined the nucleotide sequence of alanyl $t$ RNA, the sequences of three other species of $t$ RNA have revealed certain features common to the four molecules. Moreover, the structure of double helical RNA, that of reovirus, has been determined by X-ray diffraction, and the importance of the phenomena of base stacking in non-helical regions of nucleic acid molecules has been recognized. Fuller and Hodgkin have used these data and the accumulated information on bond lengths and angles in ribonucleotides and nucleotides to construct their model of the anticodon loop. By restricting their effort to this small region of the $t$ RNA molecule, Fuller and Hodgkin have provided themselves with fixed points - the two free ends of the loop and a region of base-pairing. When the seven unpaired nucleotides that form the anticodon loop are arranged to maximize base stacking, taking into account all the known stereochemical constraints, there appears to be a unique structural solution for the four species of $t$ RNA: five bascs are stacked and two are in a less ordered configuration.

The model engenders confidence because of its stereochemical neatness and because it is based on two eminently reasonable assumptions--that there should be maximum base pairing and maximum base stacking. Moreover, any model must of course be reconcilable with the known biological functions of a molecule and the proposed structure of the anticodon loop is. It accommodates the genetic data on which Crick based his wobble hypothesis and it allows two $t$ RNA molecules simultancously to recognize adjacent codons of a messenger RNA molecule.

Obviously the structure of a molecule can never be proved by model building alone. Sometimes it may only show what structures are impossible, but may leave several alternative probabilities. When, however, a model accounts uniquely for all the known structural and functional properties of a molecule, it is probably substantially correct. It remains to be seen whether or not the model now proposed will stand when the nucleotide sequences of more speeics of $\iota$ RNA have been determined. Meanwhile, model building may well be used to find the probable structure of another vital part of the $t$ RNA molecule--the amino-acid recognition site. 